9. Kowdley KV, Gordon SC, Reddy KR, Rossaro L, Bernstein DE, Lawitz E, et al. Ledipasvir and sofosbuvir for 8 or 12 weeks for chronic HCV without cirrhosis. N Engl J Med. 2014;370,1879-88. http://dx.doi.org/10.1056/NEJMoa1402355

10. Feld JJ, Kowdley KV, Coakley E, Sigal S, Nelson DR, Crawford D, et al. Treatment of HCV with ABT-450/r-ombitasvir and dasabuvir with ribavirin. N Engl J Med. 2014;370:1594-603. http://dx.doi. org/10.1056/NEJMoa1315722

Address for correspondence: Anne C. Spaulding, Rollins School of Public Health, Department of Epidemiology, 1518 Clifton Rd, Room 3033, Atlanta, GA 30322, USA; email: ASpauld@emory.edu

\title{
Correction: Vol. 20, No. 3
}

The name of author Magnus Rasmussen was misspelled in the article Septic Arthritis Caused by Streptococcus suis Serotype 5 in Pig Farmer (C. Gustavsson, M. Ramussen). The article has been corrected online (http://wwwnc.cdc. gov/eid/article/20/3/13-0535_article).

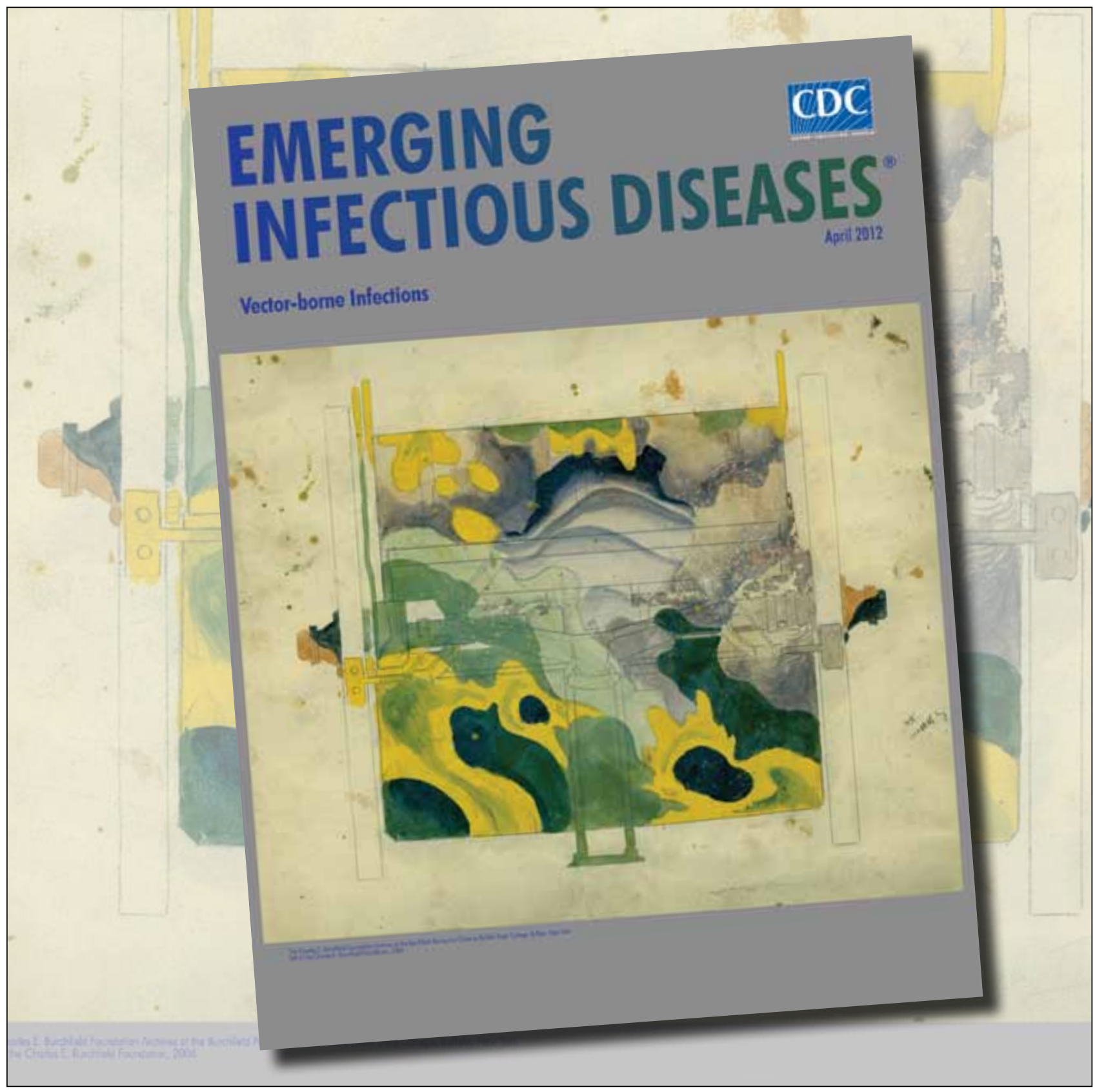

